\title{
Active layer analysis of interpenetrating heterojunction organic thin-film solar cells by X-ray photoelectron spectroscopy
}

Tetsuro Hori, Akitoshi Semba, Sunghwan Lee, Hitoshi Kubo, Akihiko Fujii*, and Masanori Ozaki

Division of Electrical, Electronic and Information Engineering, Graduate School of Engineering, Osaka University, 2-1 Yamada-oka, Suita, Osaka 565-0871, Japan

\begin{abstract}
The active layer analysis of interpenetrating heterojunction organic thin-film solar cells by X-ray photoelectron spectroscopy (XPS) has been studied. The interpenetrating heterojunction structure based on poly(3-hexylthiophene) (P3HT) and fullerene $\left(\mathrm{C}_{60}\right)$ could be fabricated by spin-coating P3HT onto a deposited $\mathrm{C}_{60}$ film. The composition ratios of $\mathrm{P} 3 \mathrm{HT}$ and $\mathrm{C}_{60}$ in the interpenetrating heterojunction active layer in the depth direction and the interface morphology between the P3HT and $\mathrm{C}_{60}$ layers have been clarified by XPS with argon ion etching and scanning electron microscopy. It has been found that the donor-acceptor interface of the interpenetrating heterojunction active layer is formed by the rod-shaped $\mathrm{C}_{60}$ particles with a width of approximately $100 \mathrm{~nm}$ and $\mathrm{C}_{60}$ grains with a size of $10-50 \mathrm{~nm}$.
\end{abstract}

*E-mail address: afujii@eei.eng.osaka-u.ac.jp 


\section{Introduction}

Organic thin-film

solar cells utilizing conducting polymers have attracted considerable attention as next-generation solar cells from the viewpoints of light weight, flexiblility, and low cost. Organic thin-film solar cells based on conducting polymers have been investigated since the discovery of photoluminescence quenching [1], photoinduced charge transfer [2], and photoconduction enhancement [3] between a conducting polymer and fullerene $\left(\mathrm{C}_{60}\right)$.

Two typical device structures, a conducting polymer- $\mathrm{C}_{60}$ composite structure [4,5] and a layered structure [6], have mainly been studied in the field of organic thin-film solar cells. For the optimization of the device structures, the ideal active layer morphology of organic thin-film solar cells has been discussed [7,8]. The ideal active layer morphology fulfills the following three conditions. Firstly, donor and acceptor molecules are separated completely. Secondly, there are only donor molecules at the hole-collecting electrode interface and only acceptor molecules at the electron-collecting electrode interface. Finally, the distances between donor and acceptor molecules are almost the same as the exciton diffusion lengths of active layer materials.

In the device structure with the ideal active layer morphology, the photoinduced charge transfer occurs efficiently because of the large donor-acceptor 
interface area, and the generated holes and electrons can be efficiently transported in the p-type (donor) and n-type (acceptor) materials towards the positive and negative electrodes, respectively. Recently, we have developed a simple and effective method for fabricating such complicated donor-acceptor interfaces and reported on the improvement of energy conversion efficiency [9-12]. This active layer structure is called the "interpenetrating heterojunction" structure.

It is important for the improvement of photovoltaic properties on organic thin-film solar cells to control the active layer morphology precisely, that is, donor-acceptor micro-phase separation [13-15]. Donor-acceptor micro-phase separation plays an important role in carrier generation and transport, and affects the device performance. Therefore, precise analysis techniques for the donor-acceptor interface in organic thin-film solar cells are required for controlling the interface [16-18].

The analysis technique for the interpenetrating heterojunction structure with a three-dimensional complicated donor-acceptor network has not been established. The interpenetrating heterojunction structure could be observed by scanning electron microscopy (SEM) [19] or atomic force microscopy (AFM) [20], however, only two-dimensional information, such as the surface morphology or cross-section of the active layer, was observed.

In this paper, we report on the active layer analysis of the depth direction in an interpenetrating heterojunction organic thin-film solar cell by X-ray photoelectron 
spectroscopy (XPS). XPS can analyze the composition ratio of several atoms at a surface sensitively, and it can also analyze the depth direction with an etching process [21-23]. In addition, the donor-acceptor interface of the interpenetrating heterojunction active layer is discussed by taking the surface morphology in the SEM observation after etching into consideration.

\section{Experimental details}

Poly(3-hexylthiophene) (P3HT) (Merck Inc.) and $\mathrm{C}_{60}$ (Frontier Carbon Ltd.) were used as purchased in this study. Silicon substrates, the surface roughness of which was less than $0.1 \mathrm{~nm}$, were used in this study.

The active layer with an interpenetrating heterojunction structure was fabricated by the following method. $\mathrm{C}_{60}$ films with a thickness of approximately $100 \mathrm{~nm}$ were deposited by thermal evaporation at a rate of $2.7-2.9 \mathrm{~nm} / \mathrm{min}$ onto a silicon substrate at a pressure of $10^{-4} \mathrm{~Pa}$. The chloroform solution of P3HT, the concentration of which was $16.6 \mathrm{mg} / \mathrm{ml}$, was spin-coated onto the $\mathrm{C}_{60}$ layer at $500 \mathrm{rpm}$ for $5 \mathrm{sec}$ and $1500 \mathrm{rpm}$ for $30 \mathrm{sec}$ to fabricate the $\mathrm{C}_{60} / \mathrm{P} 3 \mathrm{HT}$ interpenetrating layer. The thickness of the P3HT film was approximately $140 \mathrm{~nm}$ on a glass substrate under the same conditions.

The active layers with bi-layer and bulk heterojunction structures were also fabricated for comparison. The bi-layer structure was composed of a spin-coated P3HT 
film onto a silicon substrate and an evaporated $\mathrm{C}_{60}$ film. The thicknesses of P3HT and $\mathrm{C}_{60}$ were approximately $140 \mathrm{~nm}$ and $20 \mathrm{~nm}$, respectively. The active layer with a bulk heterojunction structure of P3HT and a fullerene derivative, 1-(3-methoxy-carbonyl)propyl-1-1-phenyl-(6,6)C61 (PCBM), was fabricated by spin-coating the mixed chloroform solution of P3HT and PCBM onto a silicon substrate. $10 \mathrm{mg}$ of P3HT and $10 \mathrm{mg}$ of PCBM were dissolved in $1 \mathrm{ml}$ of chloroform solvent, and the thickness of the bulk heterojunction film was approximately $220 \mathrm{~nm}$.

The active layers were etched by argon ion. Argon ion etching was carried out under constant conditions, such as, an acceleration voltage of $0.5 \mathrm{kV}$, an emission current of $30 \mathrm{~mA}$, an argon gas pressure of approximately $10^{-2} \mathrm{~Pa}$, and an incident angle of $30^{\circ}$. XPS spectra of the active layers were measured by X-ray photoelectron spectroscope (Shimadzu ESCA-850) under $10^{-7} \mathrm{~Pa}$, and the binding energies were determined by using that of $3 \mathrm{~d}$ orbital of silver as a reference data. The surface morphologies of the interpenetrating heterojunction active layer were observed by using a field-emission scanning electron microscope (FE-SEM: Hitachi S-4300) before and after etching, the acceleration voltage of which was $10 \mathrm{kV}$.

\section{Results and discussion}

Figure 1 shows the XPS spectra and molecular structures of P3HT and $\mathrm{C}_{60}$, which were used as active layer materials. The sharp XPS peak corresponding to the $1 \mathrm{~s}$ 
orbital of carbon atoms was observed at approximately $284 \mathrm{eV}$ in the $\mathrm{C}_{60}$ film. On the other hand, the XPS peaks corresponding to the $2 \mathrm{~s}$ and $2 \mathrm{p}$ orbitals of sulfur atoms, which exist in the thiophene ring, were also observed at approximately $228 \mathrm{eV}$ and 164 $\mathrm{eV}$, respectively, as well as that in the $1 \mathrm{~s}$ orbital of carbon atoms in the P3HT films. Another small XPS peak was observed at approximately $530 \mathrm{eV}$, which corresponds to the remaining oxygen atoms in the XPS equipment. The composition ratio of the P3HT thin film was calculated to be $91.8 \%$ carbon atoms, $7.0 \%$ sulfur atoms, and $1.2 \%$ oxygen atoms. The composition ratio of materials in the active layers was determined by using these percentages, especially the percentage of sulfur atoms, because $\mathrm{C}_{60}$ and P3HT could not be distinguished from the XPS intensities of carbon atoms.

Figure 2 shows the argon ion etching time dependences of the composition ratios of carbon and sulfur atoms, namely, the bi-layer, bulk heterojunction, and interpenetrating heterojunction structures. The active layer materials can be analyzed in the depth direction by XPS with argon ion etching, because the etching time corresponds to the depth of the active layer.

In the bi-layer structure, the XPS peaks originating from sulfur atoms were not observed up to 10 minutes of etching, that is, only $\mathrm{C}_{60}$ existed on top of the bi-layer structure. By etching for more than 10 minutes, the composition ratio of sulfur atoms markedly increased to reach $7.0 \%$, which indicates that the P3HT ratio was $100 \%$ and the composition ratio of carbon atoms decreased, as shown in Fig. 2(a). Therefore, it is 
considered that the $\mathrm{P} 3 \mathrm{HT}$ and $\mathrm{C}_{60}$ layers obviously separated in the bi-layer structure.

In the bulk heterojunction structure, the composition ratio of sulfur atoms was almost constant at 2.8-3.2\% up to 22 minutes of etching, as shown in Fig. 2(b), that is, the ratio of $\mathrm{P} 3 \mathrm{HT}$ was estimated to be $40-46 \%$ in the active layer. By etching for longer than 22 minutes, the composition ratios of both carbon and sulfur atoms markedly decreased, and silicon atoms in the substrate started to be detected. In spite of the flat surface of Si substrate, the beginning of the detection of silicon atoms was due to the incomplete uniformity of the argon ion etching in plane for the organic films. By etching for longer than 28 minutes, the composition ratios of both carbon and sulfur atoms were approaching to $0 \%$, whereas silicon atom was approximately $100 \%$. Therefore, it is considered that $\mathrm{P} 3 \mathrm{HT}$ and $\mathrm{C}_{60}$ were distributed homogeneously in the bulk heterojunction structure.

In the case of the interpenetrating heterojunction structure, the composition ratio of sulfur atoms was $6.7 \%$, that is, the ratio of $\mathrm{P} 3 \mathrm{HT}$ was estimated to be $96 \%$, at the top surface of the active layer. The residual component of $4 \%$ seems to be due to $\mathrm{C}_{60}$ molecules. After only 2 minutes of etching, the composition ratio of sulfur atoms decreased to $3.5 \%$, which indicates that the $\mathrm{P} 3 \mathrm{HT}$ ratio was $50 \%$. Therefore, it is considered that P3HT covered the top surface of the active layer with the interpenetrating heterojunction structure. By the subsequent etching in the depth direction, the composition ratio of carbon atoms gradually increased, whereas the 
composition ratio of sulfur atoms gradually decreased, which indicates that the component ratio of $\mathrm{C}_{60}$ in the film increased monotonically and that of $\mathrm{P} 3 \mathrm{HT}$ decreased constantly. Therefore, it is considered that the main material gradually changed from $\mathrm{P} 3 \mathrm{HT}$ to $\mathrm{C}_{60}$ in the depth direction of the interpenetrating heterojunction structure.

The relationships between argon ion etching time and etched thin film thickness of $\mathrm{P} 3 \mathrm{HT}$ and $\mathrm{C}_{60}$ were investigated in order to evaluate the etching rates of these active layer materials. The film thicknesses were determined by the absorbance of thin films and AFM measurement. As shown in Fig. 3, the etching rate of the P3HT film was $9.5 \mathrm{~nm} / \mathrm{min}$ and that of the $\mathrm{C}_{60}$ film was $1.7 \mathrm{~nm} / \mathrm{min}$, that is, the P3HT film could be etched 5.6 times faster than the $\mathrm{C}_{60}$ film.

In the case of a simple bi-layer structure, the top surface of the bottom layer, that is, the donor-acceptor interface of the bi-layer, should appear with the complete removal of the top layer by etching. Although the interpenetrating heterojunction structure is expected to be complicated from our previous works [19,20], the P3HT layer could be removed mainly owing to the obvious difference in etching rate and only the $\mathrm{C}_{60}$ layer remains on the substrate with etching for an appropriate time. If the interpenetrating heterojunction structure is simplified as a bi-layer structure of 140-nm-thick P3HT and 100-nm-thick $\mathrm{C}_{60}$ films, the P3HT top layer must be removed completely and the $\mathrm{C}_{60}$ bottom layer of about $75 \%$ should remain after etching for 30 minutes. It is considered, therefore, that 30 minutes of etching is sufficient for clarifying 
the buried interface structure.

Figures 4(a) and 4(b) show the surface SEM images of the interpenetrating heterojunction structure before and after argon ion etching. Before etching, a comparatively planar surface was observed except for rod-shaped objects of approximately $1 \mu \mathrm{m}$ length. After etching the interpenetrating heterojunction structure in the depth direction, many rod-shaped aggregates of approximately $1 \mu \mathrm{m}$ length and $100 \mathrm{~nm}$ width were observed clearly. Since 30 minutes of etching is sufficient for removing the P3HT layer, these rod-shaped aggregates must be composed of $\mathrm{C}_{60}$ molecules. It is considered that the chloroform solvent dissolved the $\mathrm{C}_{60}$ layer slightly, when P3HT was spin-coated, and the rod-shaped particles of $\mathrm{C}_{60}$ were formed by re-aggregation. In our previous work, a similar nanostructured $\mathrm{C}_{60}$, which can be fabricated by spin-casting an organic solvent onto the $\mathrm{C}_{60}$ thin film, has been reported [24], therefore, $\mathrm{C}_{60}$ molecules tend to form rod-shaped aggregates by the quick solution process even in the interpenetrating heterojunction active layer. Moreover, small $\mathrm{C}_{60}$ grains with a size of 10-50 nm were observed in the magnified SEM image after etching, as shown in Fig. 4(c).

From the results in this study, the interpenetrating heterojunction structure is observed to have a complicated donor-acceptor interface formed by rod-shaped $\mathrm{C}_{60}$ particles with a width of approximately $100 \mathrm{~nm}$ and $\mathrm{C}_{60}$ grains with a size of 10-50 nm. It is considered that the photoinduced charge separation efficiency would be improved 
by increasing the number of $\mathrm{C}_{60}$ nanorods and controlling their direction to be perpendicular to the substrate as the future strategy for the active layer with an interpenetrating heterojunction structure.

\section{Conclusions}

We reported on the active layer analysis of the interpenetrating heterojunction organic thin-film solar cells by XPS measurement and SEM observation with argon ion etching. The composition ratios of carbon and sulfur atoms in the depth direction were clarified for typical active layer structures, such as, the bi-layer, bulk heterojunction, and interpenetrating heterojunction structures. The donor-acceptor interface in the interpenetrating heterojunction structure was discussed from the results of SEM observation for the active layer film, the P3HT layer of which was removed by argon ion etching. The active layer with the interpenetrating heterojunction was observed to possess a complicated donor-acceptor interface formed by rod-shaped $\mathrm{C}_{60}$ particles with a width of approximately $100 \mathrm{~nm}$ and $\mathrm{C}_{60}$ grains with a size of $10-50 \mathrm{~nm}$.

\section{Acknowledgments}

This work was partly supported by Grants-in-Aid for Scientific Research (A) and for the Japan Society for the Promotion of Science Fellows (No. 225630) from the Ministry of Education, Culture, Sports, Science and Technology, Japan, and by 
Advanced Low Carbon Technology Research and Development Program from the Japan Science and Technology Agency (JST-ALCA). 


\section{Figure captions}

Fig. 1 XPS spectra and molecular structures of P3HT and $\mathrm{C}_{60}$.

Fig. 2 Argon ion etching time dependences of the composition ratios of carbon and sulfur atoms of (a) bi-layer, (b) bulk heterojunction, and (c) interpenetrating heterojunction structures.

Fig. 3 The relationships between argon ion etching time and thicknesses of P3HT and $\mathrm{C}_{60}$.

Fig. 4 Surface SEM images of the interpenetrating heterojunction structure (a) before argon ion etching and (b) after etching for 30 minutes, and (c) magnified SEM image of (b). 


\section{References}

[1] S. Morita, A.A. Zakhidov, K. Yoshino, Solid State Commun. 82 (1992) 249.

[2] N.S. Sariciftci, L. Smilowitz, A.J. Heeger, F. Wudl, Science 258 (1992) 1474.

[3] K. Yoshino, X.H, Yin, S. Morita, T. Kawai, A.A. Zakhidov, Solid State Commun. 85 (1993) 85 .

[4] G. Yu, K. Pakbaz, A.J. Heeger, Appl. Phys. Lett. 64 (1994) 3422.

[5] T. Umeda, H. Noda, T. Shibata, A. Fujii, K. Yoshino, M. Ozaki, Jpn. J. Appl. Phys. 45 (2006) 5241.

[6] S. Morita, A.A. Zakhidov, K. Yoshino, Jpn. J. Appl. Phys. 32 (1993) 873.

[7] K. Yoshino, K. Tada, A. Fujii, E.M. Conwell, A.A. Zakhidov, IEEE Trans. Electron. Devices 44 (1997) 1315.

[8] S. Günes, H. Neugebauer, N.S. Sariciftci, Chem. Rev. 107 (2007) 1324.

[9] T. Hori, T. Shibata, V. Kittichungchit, H. Moritou, J. Sakai, H. Kubo, A. Fujii, M. Ozaki, Thin Solid Films 518 (2009) 522.

[10] V. Kittichungchit, T. Hori, H. Moritou, H. Kubo, A. Fujii, M. Ozaki, Thin Solid Films 518 (2009) 518.

[11]T. Hori, H. Moritou, N. Fukuoka, J. Sakamoto, A. Fujii, M. Ozaki, Materials 3 (2010) 4915.

[12]T. Hori, V. Kittichungchit, H. Moritou, H. Kubo, A. Fujii, M. Ozaki, Materials 3 (2010) 4939. 
[13] J. Hollinger, A. A. Jahnke, N. Coombs, D. S. Seferos, J. Am. Chem. Soc. 132 (2010) 8546.

[14]Q. Tai, J. Li, Z. Liu, Z. Sun, X. Zhao, F. Yan, J. Mater. Chem. 21 (2011) 6848.

[15] Y. C. Huang, G. C. Welch, G. C. Bazan, M. L. Chabinyc, W. F. Su, Chem. Commun. 48 (2012) 7250.

[16]H. X. Wei, J. Li, Z. Q. Xu, Y. Cai, J. X. Tang, Y. Q. Li, Appl. Phys. Lett. 97 (2010) 083302.

[17]R. Meier, M. A. Ruderer, A. Diethert, G. Kaune, V. Körstgens, S. V. Roth, P. MüllerBuschbaum, J. Phys. Chem. B 115 (2011) 2899.

[18] A. J. Parnell, A. J. Cadby, O. O. Mykhaylyk, A. D. F. Dunbar, P. E. Hopkinson, A. M. Donald, R. A. L. Jones, Macromolecules 44 (2011) 6503.

[19]H. Mizukami, T. Umeda, H. Noda, T. Shibata, A. Fujii, M. Ozaki, J. Phys. D: Appl. Phys. 39 (2006) 1521.

[20]T. Umeda, Y. Hashimoto, H. Mizukami, A. Fujii, K. Yoshino, Jpn. J. Appl. Phys. 44 (2005) 4155.

[21]Z. Xu, L. M. Chen, G. Yang, Adv. Funct. Mater. 19 (2009) 1227.

[22] S. Yamakawa, K. Tajima, K. Hashimoto, Org. Electron. 10 (2009) 511.

[23] S. D. Yambem, K. S. Liao, N. J. Alley, S. A. Curran, J. Mater. Chem. 22 (2012) 6894.

[24]H. Mizukami, M. Ojima, S. Hiwatashi, H. Araki, A. Fujii, M. Ozaki, K. Yoshino, 
Jpn. J. Appl. Phys. 44 (2005) L851. 
Figure 1

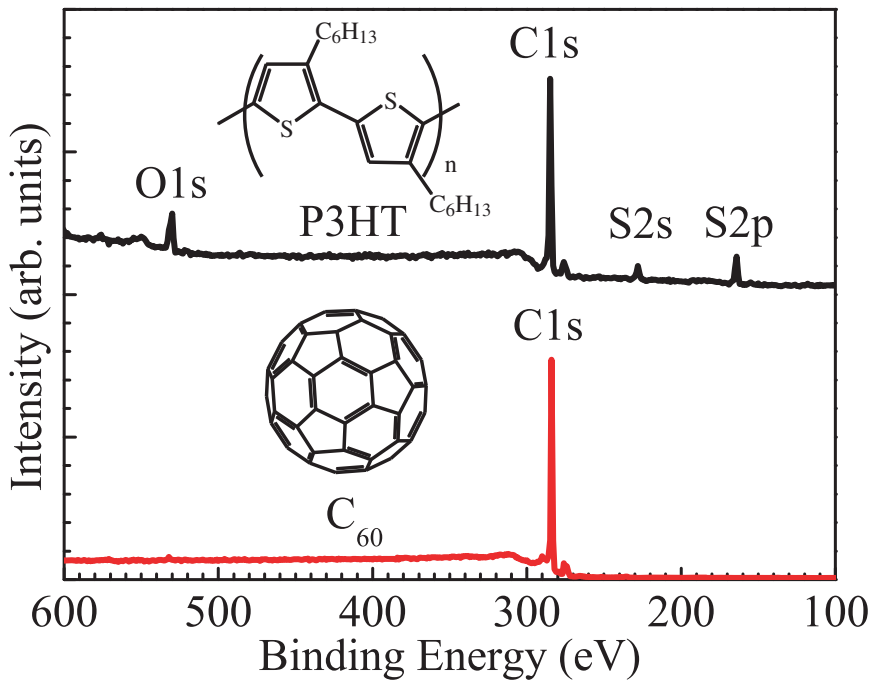



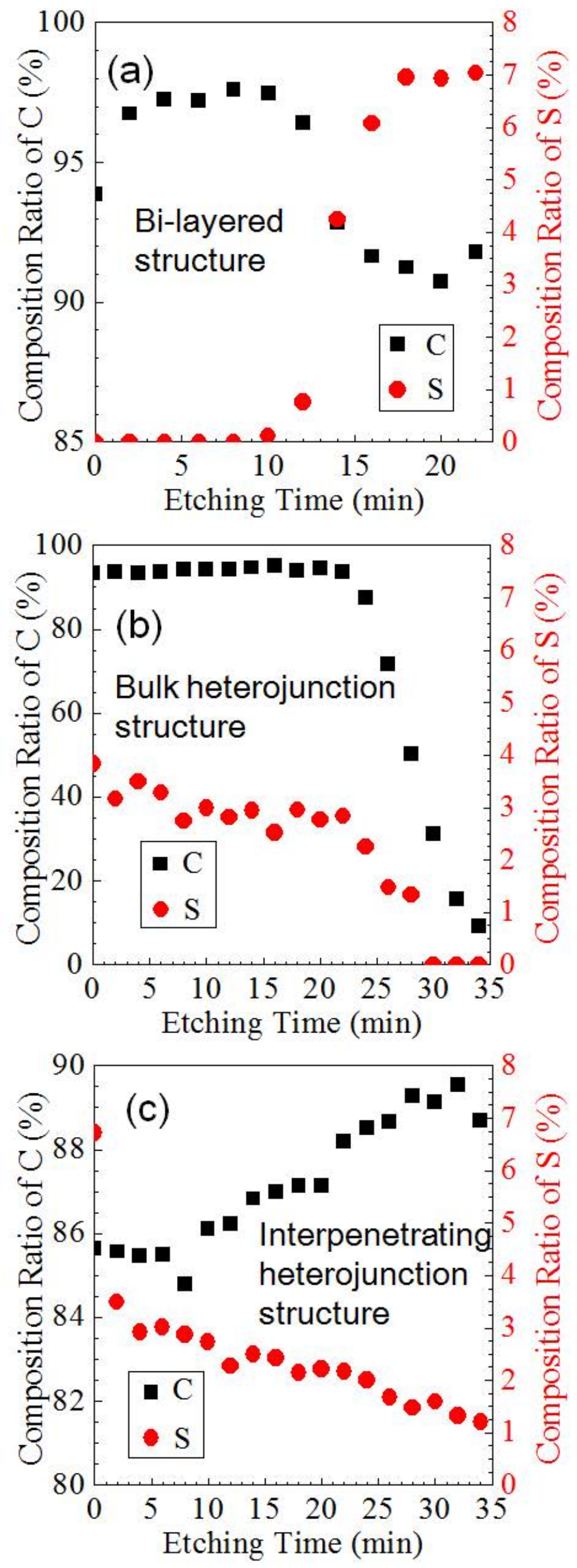
Figure 3

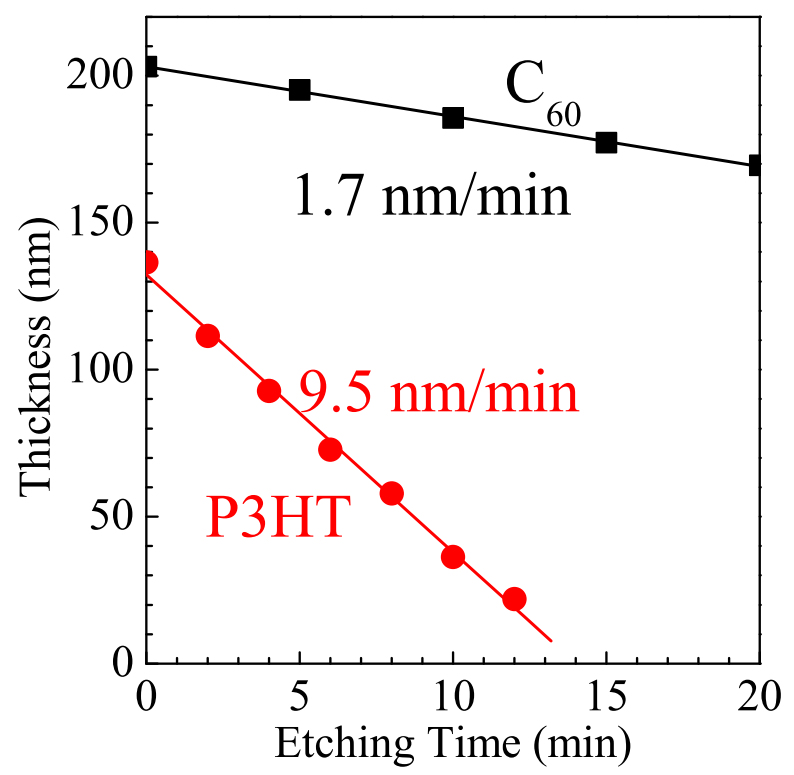




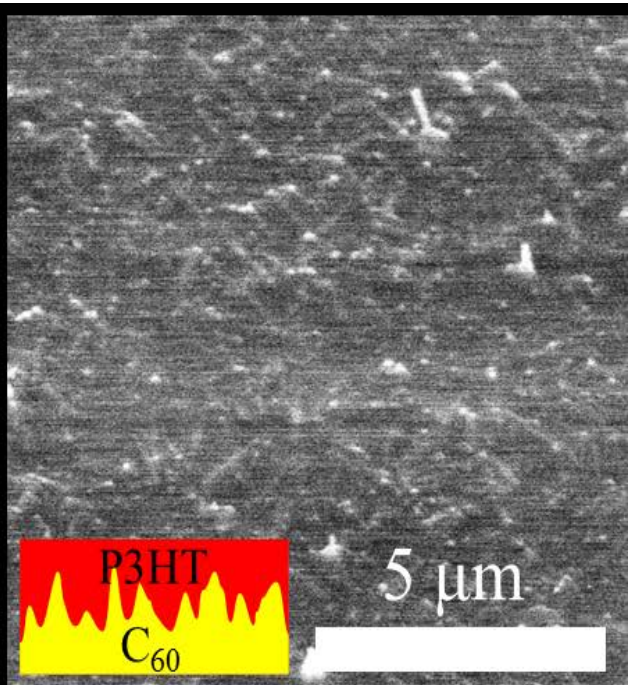

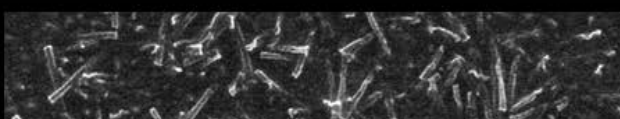

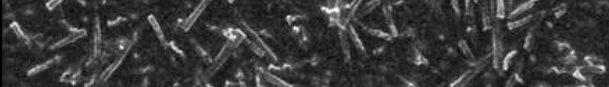

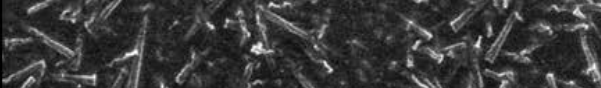

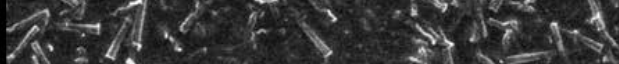

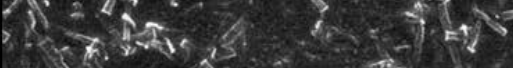

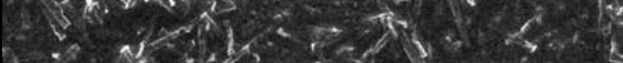

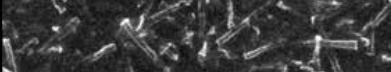

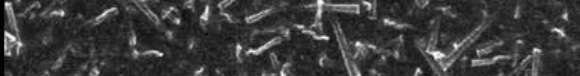

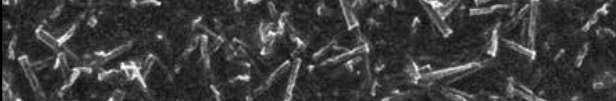

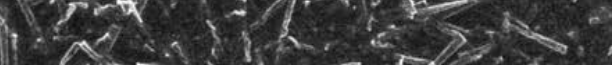

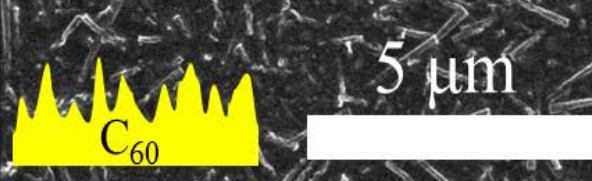

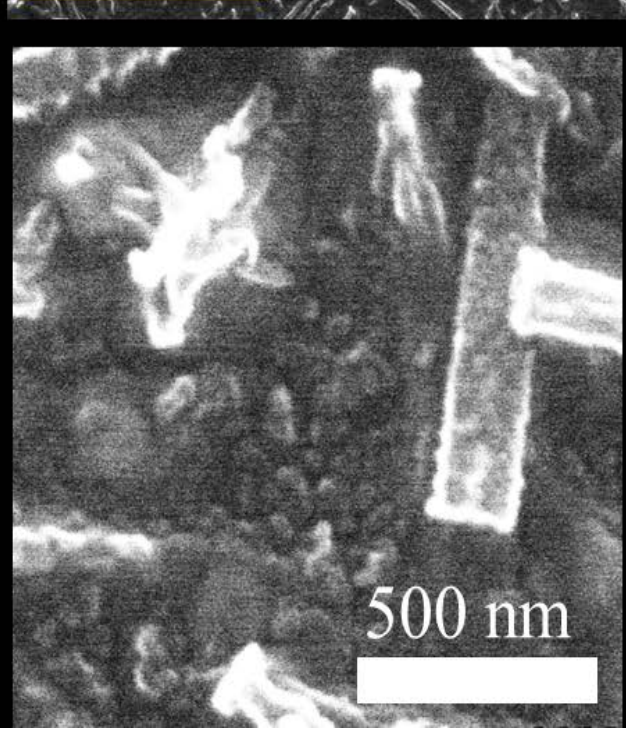

